\title{
A General Route to Bicyclo[1.1.1]pentanes through Photoredox Catalysis
}

Jeremy Nugent, ${ }^{\dagger, \S}$ Carlos Arroniz, ${ }^{\dagger, \S}$ Bethany R. Shire, ${ }^{\dagger}$ Alistair J. Sterling, ${ }^{\dagger} \bigcirc$ Helena D. Pickford, ${ }^{\dagger}$ Marie L. J. Wong, ${ }^{\dagger}$ Steven J. Mansfield, ${ }^{\dagger}$ Dimitri F. J. Caputo, ${ }^{\dagger}$ Benjamin Owen, ${ }^{\dagger}$ James J. Mousseau, Fernanda Duarte, $*, \oplus$ and Edward A. Anderson $*, \dagger \odot$

${ }^{\dagger}$ Chemistry Research Laboratory, University of Oxford, 12 Mansfield Road, Oxford OX1 3TA, United Kingdom

${ }^{\ddagger}$ Pfizer Worldwide Research and Development, Eastern Point Road, Groton, Connecticut 06340, United States

Supporting Information

ABSTRACT: Photoredox catalysis has transformed the landscape of radical-based synthetic chemistry. Additions of radicals generated through photoredox catalysis to carbon-carbon $\pi$ bonds are well-established; however, this approach has yet to be applied to the functionalization of carbon-carbon $\sigma$-bonds. Here, we report the first such use of photoredox catalysis to promote the addition of organic halides to the carbocycle [1.1.1]propellane; the product bicyclo[1.1.1]pentanes (BCPs) are motifs of high importance in the pharmaceutical industry and in materials chemistry. Showing broad substrate scope and functional group tolerance, this methodology results in the first examples of bicyclopentylation of $s p^{2}$ carbon-halogen bonds to access (hetero)arylated BCPs, as well as the functionalization of nonstabilized $s p^{3}$ radicals. Substrates containing alkene acceptors allow the single-step construction of polycyclic bicyclopentane products through unprecedented atom transfer radical cyclization cascades, while the potential to accelerate drug discovery is demonstrated through late-stage bicyclopentylations of natural productlike and druglike molecules. Mechanistic investigations demonstrate the importance of the photocatalyst in this chemistry and provide insight into the balance of radical stability and strain relief in the reaction cycle.

KEYWORDS: photoredox catalysis, bicyclo[1.1.1]pentane, strain relief, cascade reaction, mechanistic study, [1.1.1]propellane

\section{INTRODUCTION}

Bicyclo[1.1.1]pentanes (BCPs) are the subject of much interest in medicinal chemistry as surrogates for arene, ${ }^{1}$ tertbutyl, ${ }^{2}$ and acetylene groups, ${ }^{3}$ displaying improved pharmacokinetic properties, compared to their parent motifs, while maintaining substituent geometry (Figure 1a). ${ }^{4}$ BCPs are most commonly accessed through ring-opening reactions of [1.1.1]propellane (tricyclo[1.1.1.0 $\left.0^{1,3}\right]$ pentane/'TCP'); ${ }^{5}$ however, the synthesis of carbon-substituted BCPs has typically required harsh reaction conditions, such as heating with organometallic reagents ${ }^{3,6}$ or high-pressure mercury lamp irradiation (Figure 1b), ${ }^{7}$ which are incompatible with the synthesis of complex targets containing this motif. These drawbacks hamper the application of bicyclo[1.1.1]pentanes in medicinal and agrochemistry settings.

In previous work, we described the use of triethylborane to initiate atom transfer radical addition (ATRA) reactions of activated alkyl halides with [1.1.1] propellane. ${ }^{8}$ However, this chemistry showed limitations in functional group tolerance (e.g., amines and aldehydes) and was unable to access BCPs with $s p^{2}$ substituents such as arenes and heteroarenes, which are highly desirable for medicinal chemistry appliations. We questioned whether photoredox catalysis ${ }^{9}$ could overcome these restrictions, thus enabling the synthesis of BCP derivatives not possible to date. The photoredox activation of carbon-halogen bonds to access carbon-centered radicals is well-established, but despite many examples of addition of these intermediates to carbon-carbon $\pi$-bonds, ${ }^{10}$ equivalent additions to carbon-carbon $\sigma$-bonds remain unknown (Figure 1c).

Here, we describe the realization of photoredox-catalyzed ATRA reactions of organic halides with TCP, which represents the first example of photoredox catalysis in carbon-carbon $\sigma$ bond functionalization. ${ }^{11}$ This strategy not only enables additions of (hetero)aryl radicals, but also nonstabilized alkyl radicals, providing access to a wide variety $\mathrm{BCP}$ products. We further extend this chemistry to two-component atom transfer radical cyclization (ATRC) processes, whereby one or more carbocyclic rings are formed before intermolecular radical capture by TCP. To our knowledge, such two-component ATRCs are without precedent across radical chemistry. Finally, we describe applications of this reactivity to a range of

Received: July 29, 2019

Revised: September 11, 2019

Published: September 20, 2019 


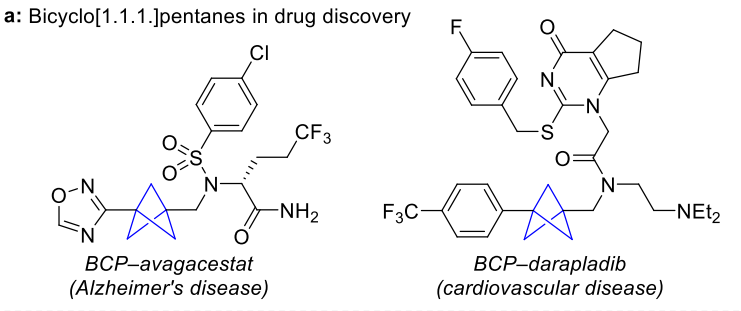

b: Known anionic and radical addition reactions of [1.1.1]propellane
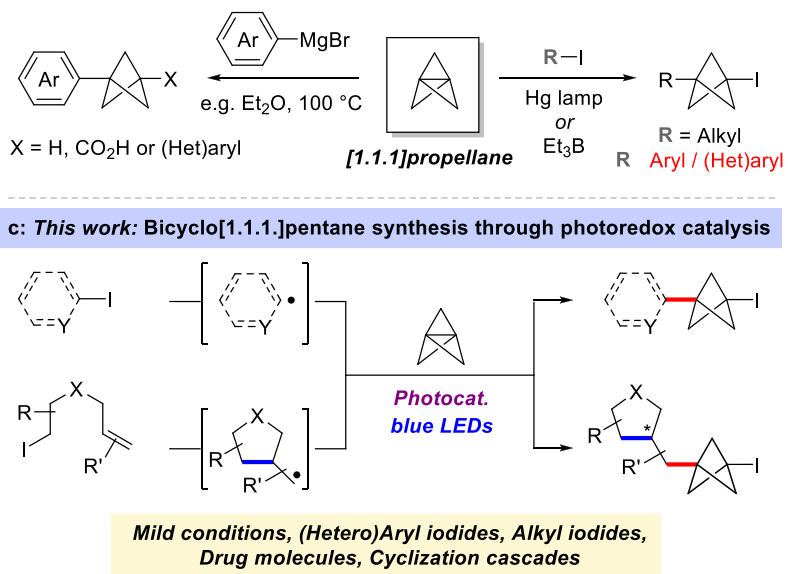

Figure 1. (a) Examples of bicyclo[1.1.1]pentane (BCP) drug analogues. (b) Entries to carbon-substituted BCPs from [1.1.1] propellane via anionic or radical addition. (c) This work: Photoredoxcatalyzed functionalization of [1.1.1]propellane.

biomolecules and pharmaceutical/agrochemical derivatives, and mechanistic studies that explore the balance between radical initiation by the photocatalyst and genuine photoredox catalysis.

\section{RESULTS AND DISCUSSION}

Benzyl iodide, which is a substrate that was ineffective using triethylborane initiation, ${ }^{8}$ was selected for reaction optimization (see Table 1). A range of transition-metal photocatalysts were found to be effective in this transformation (Table 1 , entries $1-4),{ }^{12}$ from which $f a c-\operatorname{Ir}(\text { ppy })_{3}(2.5 \mathrm{~mol} \%$, blue LED irradiation) emerged as a suitable and readily available catalyst. Pivalonitrile proved a superior solvent to acetonitrile (Table 1, entry 7), ${ }^{13}$ with low yields observed in other media (Table 1 , entries 8,9 ), and in the absence of catalyst or light (entries 10 and 11). Two equivalents of TCP led to optimal conversion, with incomplete reaction observed below this loading, ${ }^{14}$ and lower yields due to the formation of "staffane" oligomers (multiple additions to TCP) when above. ${ }^{12,15}$ The optimized conditions (Table 1, entry 7) gave bicyclopentane 3 in $87 \%$ yield.

We next explored whether this novel reactivity could be applied to other substrates not suitable for classical radical chain methods, such as aryl and heteroaryl iodides; to this end, 2 -iodopyridine was subjected to an equivalent catalyst screen. To our delight, $f a c-\operatorname{Ir}(\mathrm{ppy})_{3}$ again proved successful and superior to other transition-metal catalysts (Table 1, entry 12). Interestingly, the use of the organophotocatalyst 4CzIPN proved more efficient for 2-iodopyridine, compared to the reaction with benzyl iodide (Table 1 , entry 16 versus entry 6 ).

The optimized conditions enabled the installation of the BCP motif in a wide variety of compounds, with excellent functional group tolerance (Figure 2). We first examined a
Table 1. Reaction Optimization

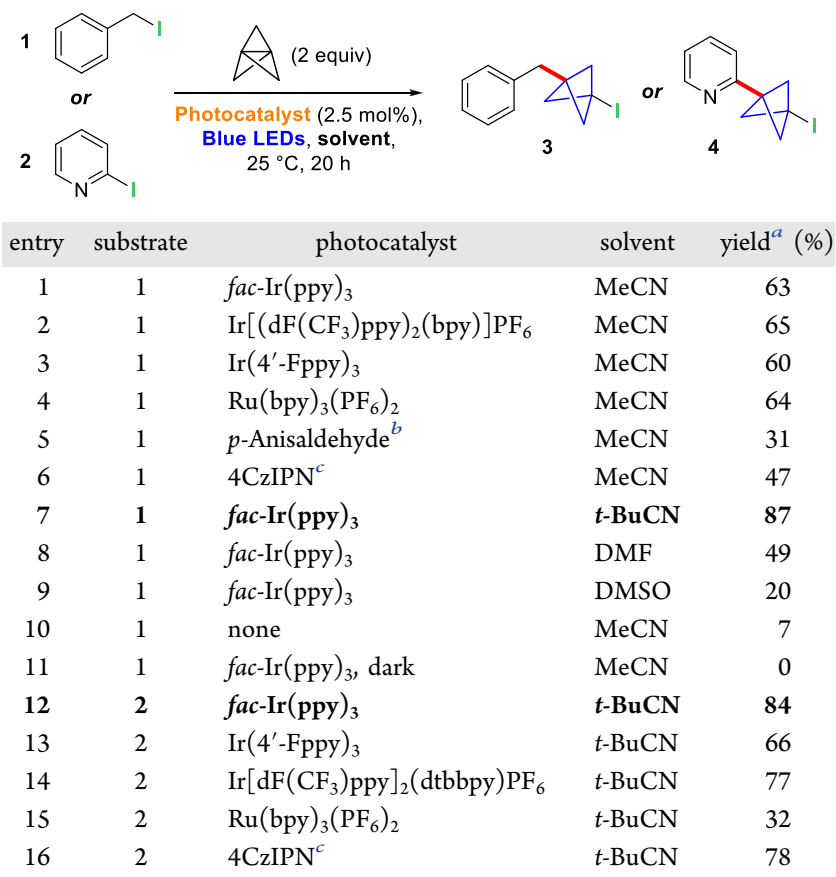

${ }^{a}$ Isolated yield. ${ }^{b} 20 \mathrm{~mol} \%$ catalyst, white LEDs. ${ }^{c} 5 \mathrm{~mol} \%$ catalyst.

range of (hetero)aromatic iodides, which are unreactive using other modes of radical initiation. Pleasingly, the use of photoredox catalysis uniquely accommodated these challenging substrates, delivering valuable (hetero)arylated BCPs 5-16 in moderate to high yields $(29 \%-87 \%)$. The flexibility of this chemistry is illustrated by the functionalization of three different positions on the pyridine ring $(\mathbf{5 - 8})$, as well as application to quinoline, isoquinoline, and pyrimidine heterocycles (11-16). Particularly notable is the selective monoATRA reaction of 2,5-diiodopyridine $(9,62 \%)$, and the double bicyclopentylation of 2,6-diiodopyridine (10, 56\%). Aryl iodides proved suitable substrates, providing electron-withdrawing substituents were present (17-21).

Unactivated primary and secondary alkyl iodides also afforded BCPs in excellent yields (22-30, 68\%-99\%). Notable examples include amines $\mathbf{2 2}$ and 23, a substrate class that is also unreactive under triethylborane initiation, and the near-quantitative yield of the BCP-phenylalanine analogue 27 on both $0.15 \mathrm{mmol}$ (99\%) and $1.5 \mathrm{mmol}$ (85\%, $1 \mathrm{~mol} \%$ fac-Ir(ppy $\left.)_{3}\right)$ scale. Benzylic and heterobenzylic iodides delivered ATRA products in good yields (31-46, 51\%$93 \%)$, as did iodides or bromides adjacent to electronwithdrawing groups $(47-64,44 \%-99 \%)$, where a wide variety of heterocyclic ketones were successfully tolerated. The high yield of aldehyde 50 (72\%) underlines the mild nature of the reaction conditions, compared with the use of triethylborane initiator $(38 \%){ }^{8}$

Reactions that form one or more rings during the course of the atom transfer process can occur when the substrate contains acceptor motifs such as alkenes. We questioned whether photoredox-generated radicals could undergo such cyclization processes prior to interception by TCP-a tandem atom transfer radical cyclization (ATRC)/bicyclopentylation reaction that accesses densely functionalized bicyclopentanes in a single step. Most photoredox-promoted cyclizations proceed in a reductive fashion, ${ }^{16}$ and of the few photoredox 


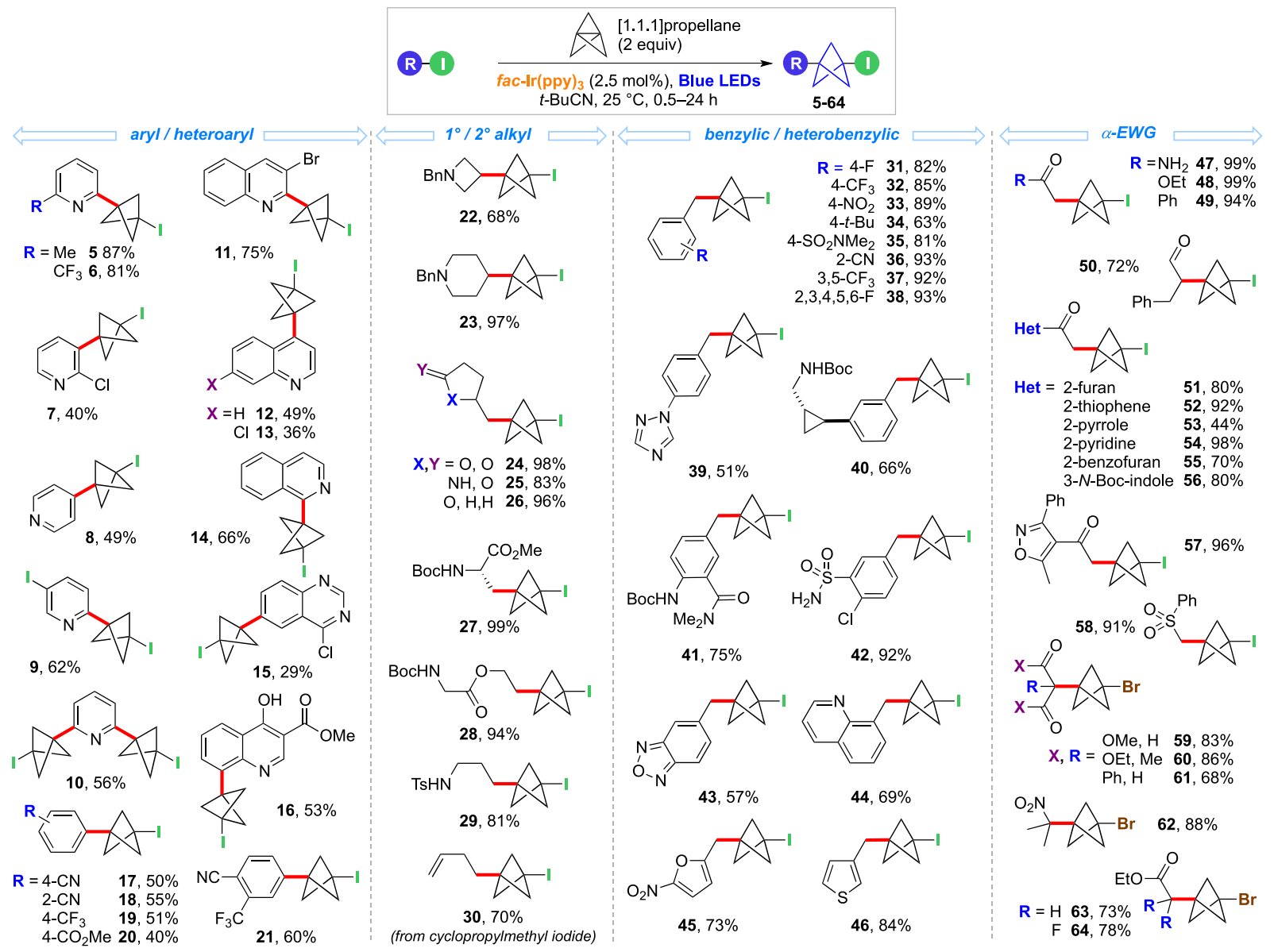

Figure 2. Bicyclopentylation of (hetero)aryl iodides, unactivated $1^{\circ} / 2^{\circ}$ alkyl iodides, (hetero)benzylic iodides, and $\alpha$-EWG halides.

ATRCs known, ${ }^{10 f, 13,17}$ to our knowledge, no two-component ATRC processes of this type have been reported. ${ }^{18}$ Challenges to this transformation include premature capture of the initially formed radical by TCP precyclization, or iodine atom abstraction post-cyclization instead of reaction with TCP, or interruption of the cascade by a catalyst quenching process.

Figure 3 shows the results of this investigation. Under equivalent conditions, tetrahydrofuran, pyrrolidine, and cyclopentane BCPs were formed in excellent yields (65-73, 60\%$98 \%$ ), with no products of direct addition of the initially formed radical to TCP observed. In many cases, these reactions were accompanied by installation of a stereocenter, which proceeded with selectivities up to $11: 1 .^{19}$ Bicyclic products could be accessed from cyclic iodides, such as fused heterocycles $74-76^{20}(68 \%-77 \%)$, which were formed as single stereoisomers at the new stereocenters. Unusual BCP spirocycles 77-79 were prepared by cyclization of the indicated precursors $(67 \%-79 \%)$, and, finally, a polycyclization to the angular triquinane $\mathbf{8 0}$ was achieved in $72 \%$ yield (9:1 dr), where two $\mathrm{C}-\mathrm{C}$ bonds are forged prior to radical capture by TCP. Such highly functionalized BCP-containing compounds are currently inaccessible by other means.

The potential of this bicyclopentylation to operate in settings relevant to medicinal chemistry research was demonstrated through late-stage diversification of various biomolecules and druglike compounds (see Figure 4). Exceptional tolerance of functional groups was observed, with BCP derivatives isolated in high yields. Dipeptides bearing serine residues were efficiently transformed to bicyclopentane dipeptides in two steps ( 81 and $\mathbf{8 2}$ ), the BCP amino acid in the latter being an analogue of the phenylalanine residue in aspartame. BCP nucleoside 83 was derived in two steps from cyclouridine, without the need for any protecting groups. High facial selectivity was observed in this process, and in the $C$ glycosylation in glucose derivative $\mathbf{8 4}$. BCP steroids 85 and 86 were obtained from corticosterone and epiandrosterone, respectively, with 86 being formed as a single diastereomer due to pyramidalization of the intermediate radical. ${ }^{20}$ Most pleasing were the successful functionalizations of iodides derived from pharmaceuticals and agrochemicals (87-92), including metronidazole (antibiotic and antiprotozoal agent), penicillin G (antibiotic), pretilachlor (pesticide), indomethacin (NSAID), and telmisartan (angiotensin II receptor antagonist).

BCP halides are useful precursors to other derivative$s,{ }^{3,7 a, c, 8,21}$ and further transformations of the iodo-BCP products were briefly explored (see Figure 4). Mild reduction of the $\mathrm{C}-\mathrm{I}$ bond in $\mathbf{8 8}$ delivered the BCP penicillin $\mathrm{G}$ analogue 93, while lithiation of piperidine adduct 23 followed by crosscoupling, ${ }^{3}$ afforded the bis-heterocycle-substituted BCP 94. Lithiation of 19 and electrophilic trapping with $\mathrm{CO}_{2}$ gave acid 95, the two-step synthesis of which compares favorably with the seven-step approach reported in work toward a darapladib analogue. ${ }^{1 \mathrm{~b}}$ Finally, the potential of the iodo-BCP framework to serve as a precursor to other useful functionalities was demonstrated by the $\mathrm{Ag}(\mathrm{I})$-promoted iodide abstraction/ rearrangement/cyclization to spirocyclic cyclobutane $\mathbf{9 6}$. 


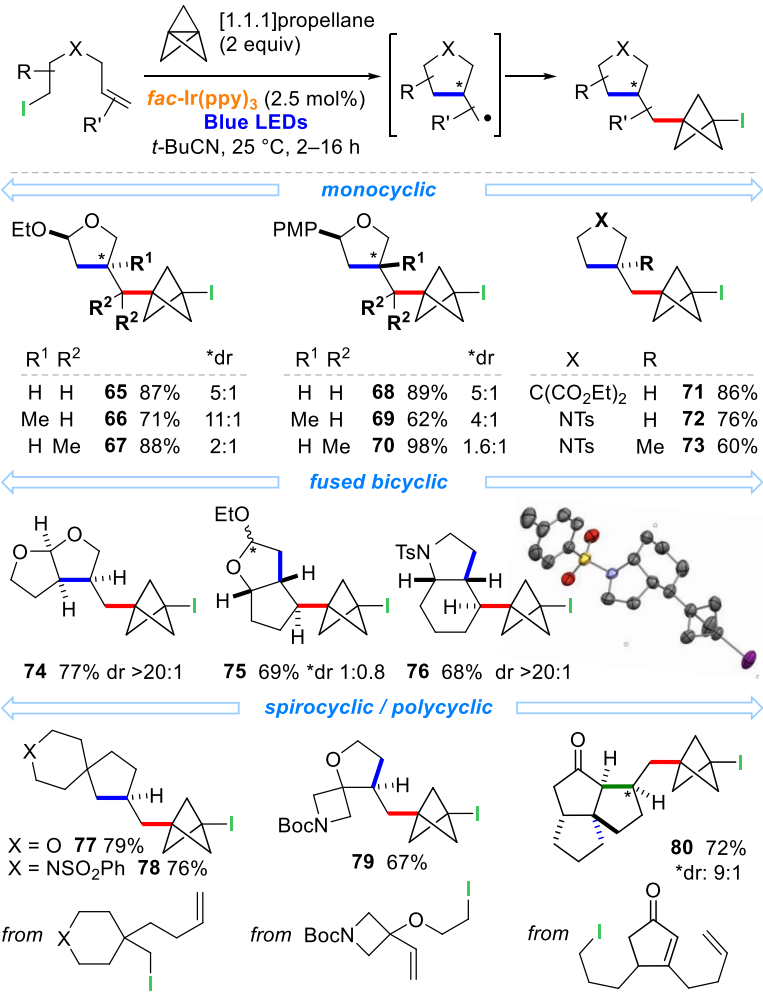

Figure 3. Two-component photoredox-catalyzed atom transfer radical cyclizations (ATRCs).

The mechanism of this strain-release ATRA is proposed to commence with outer-sphere SET from the excited state Ir(III) complex $\mathbf{A}$ to the halide substrate (see Figure 5a, $E^{\circ}\left(\mathrm{Ir}^{4+} / \mathrm{Ir}^{3+*}\right)=-1.73 \mathrm{~V}$ vs SCE $) .^{22}$ This results in reductive cleavage of the carbon-halogen bond to give radical $\mathbf{B}$, which effects strain-relief ring opening of TCP to give bicyclopentyl radical $\mathbf{C}$. This intermediate can either undergo propagation (Path a) to form the product BCP D and regenerate the chain carrier $\mathbf{B}$, or it can undergo oxidative quenching by the $\operatorname{Ir}(\mathrm{IV})$ complex to regenerate the $\operatorname{Ir}(\mathrm{III})$ catalyst (Path $\mathbf{b}, E^{\circ}\left(\mathrm{Ir}^{4+} / \mathrm{Ir}^{3+}\right)$ $=+0.77 \mathrm{~V}$ vs SCE $)^{22}$ and form bicyclopentyl cation E. Density functional theory (DFT) calculations ${ }^{23,24}$ using the example substrate 4-iodopyridine (Figure $5 \mathrm{~b}$ ) show strain-relieving addition of pyridyl radical B to TCP $\left(\Delta G=-26.3 \mathrm{kcal} \mathrm{mol}^{-1}\right)$, followed by rate-limiting propagation (TS2, $\Delta G^{\ddagger}=11.8 \mathrm{kcal}$ $\mathrm{mol}^{-1}$ ) via iodine atom abstraction from iodopyridine to complete the ATRA process (8). Although the latter step is calculated (for this substrate) to be endergonic by $\sim 2 \mathrm{kcal}$ $\mathrm{mol}^{-1}$, the resulting pyridyl radical can be efficiently sequestered by reaction with excess TCP. This pathway is in competition with polar crossover via oxidation of BCP radical $\mathrm{C}$ to nonclassical bicyclopentyl carbocation $\mathrm{E}$, which results in substantial strain relief $\left(E_{\text {cell }}=+1.92 \mathrm{~V}, \Delta G=-44.5 \mathrm{kcal}\right.$ $\mathrm{mol}^{-1}$; see the Supporting Information for a detailed discussion). E, in turn, rapidly converts to a cyclobutyl cation, which can be intercepted by iodide to afford cyclobutyl iodide $\mathbf{F}$, a rearrangement that is analogous to the cationic pathway for formation of 96 (c.f. Figure 4). Direct experimental support for this proposed sequence of events was found in the observation of small amounts of cyclobutyl BCP iodide 97, which presumably arises from a further ATRA reaction of the cyclobutyl iodide $\mathbf{F}$ ( $\mathrm{R}=4$-pyridine $)$.

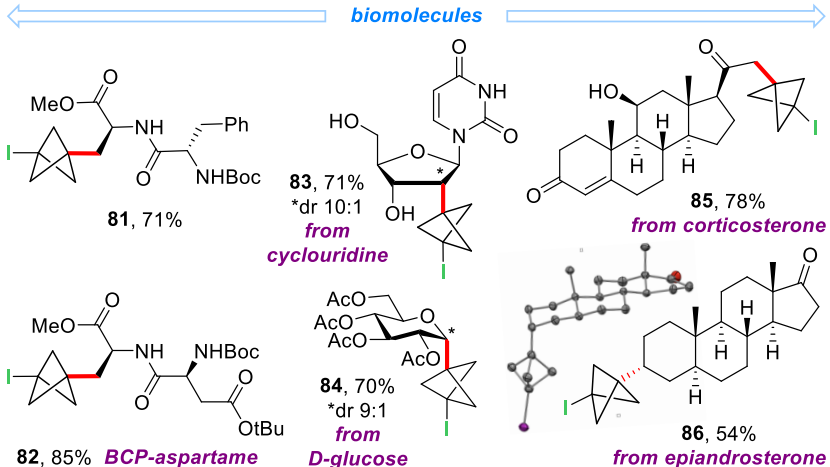

$82,85 \%$ BCP.aspartame
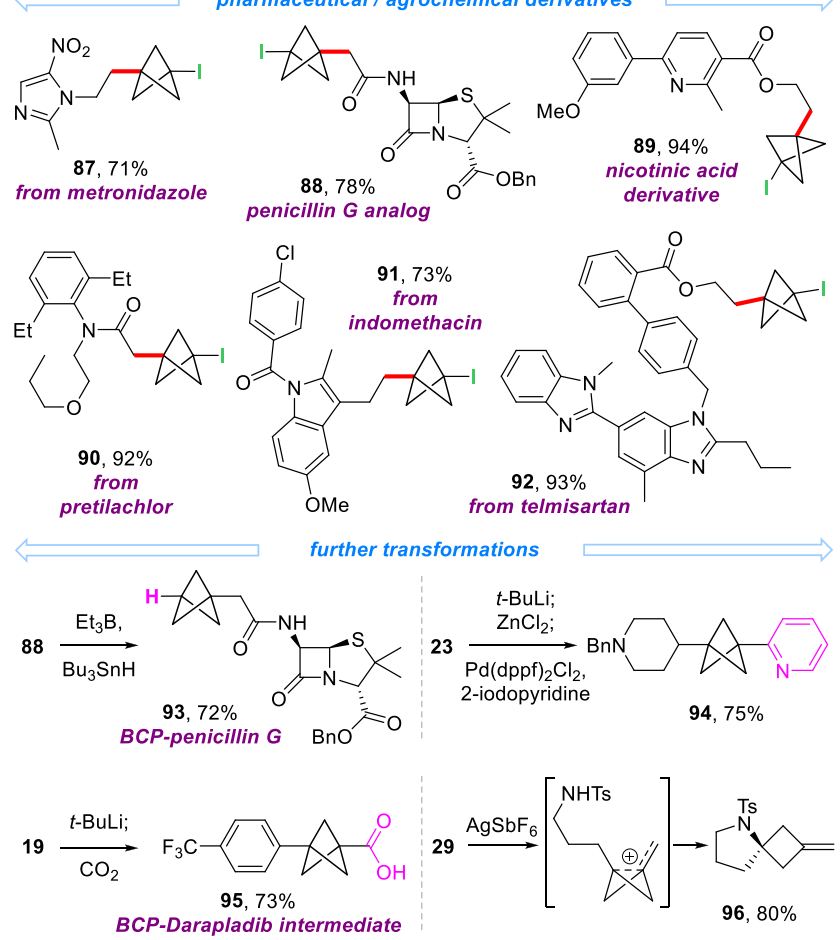

Figure 4. Bicyclopentylations of biomolecules and pharmaceuticals/ agrochemicals, and further transformations of halogenated BCP products.

To elucidate the extent to which the chain process balances with true catalysis, quantum yields were measured for a selection of substrates (Figure 5a). For ethyl iodoacetate, a quantum yield of 682 indicates a predominant propagation pathway to product 48. However, values of 7.4 for 2iodopyridine and $p$ - $\mathrm{CF}_{3}$-benzyl iodide, and 1.4 for benzyl iodide, reveal inefficient propagation and significant catalyst turnover, consistent with these substrates being poorly reactive (or unreactive) under triethylborane-initiated ATRA. These measurements underline the essential role of the photoredox catalyst in enabling additions of radicals not viable under classical "radical chain" conditions.

\section{CONCLUSION}

In conclusion, we have established a new class of photoredox reactivity where a carbon-carbon $\sigma$-bond is functionalized by photocatalyst-generated radicals. These mild conditions enable the first examples of bicyclopentylation of $s p^{2}$ carbon-iodine bonds, in addition to stabilized and nonstabilized $s p^{3} \mathrm{C}-\mathrm{X}$ bonds. We also demonstrate the first examples of two- 


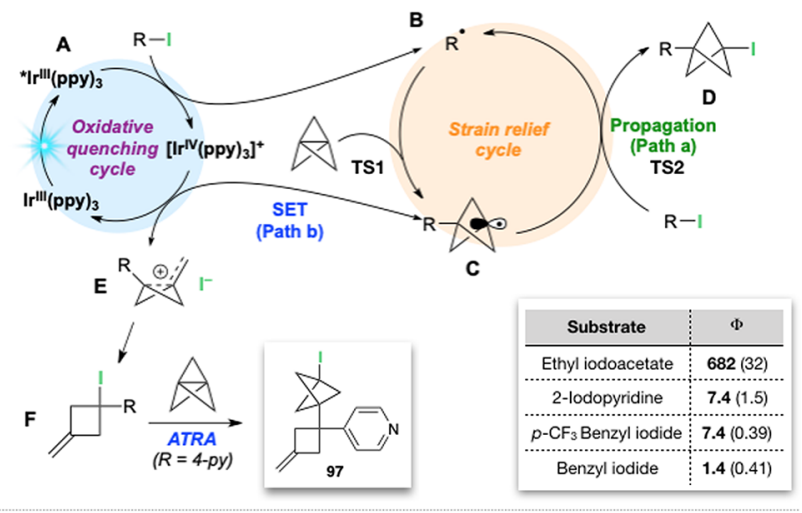

\section{b}

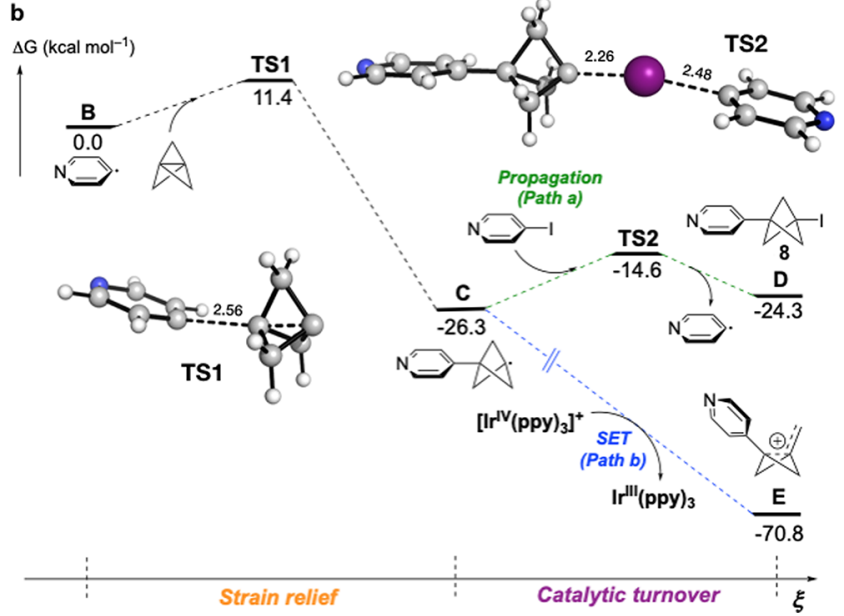

Figure 5. (a) Proposed reaction pathway for the ATRA balances propagation ("Path a") with oxidative quenching ("Path b"), as illustrated by quantum yield measurements. Standard deviations are shown in parentheses. (b) Free-energy profile calculated at the $\operatorname{SMD}(\mathrm{MeCN})-\mathrm{RI}-\mathrm{B} 2 \mathrm{PLYP}-\mathrm{D} 3 \mathrm{BJ} / \mathrm{def} 2-\mathrm{QZVPP} / / \mathrm{SMD}(\mathrm{MeCN})-\mathrm{RI}-$ $\mathrm{B} 2 \mathrm{PLYP} / \mathrm{def} 2$-TZVP level of theory for 4-iodopyridine. Bond lengths are reported in Ångstroms.

component atom-transfer radical cyclization reactions, where TCP acts as an efficient intermolecular trap following ringforming processes. Together with the late-stage derivatization of biologically relevant compounds and broad functional group tolerance, this chemistry generates bicyclopentanes that are not accessible by other routes. Given the interest in these motifs as building blocks in medicinal chemistry, agrochemistry, and materials research, this methodology has the potential for widespread applications.

\section{ASSOCIATED CONTENT}

\section{S Supporting Information}

The Supporting Information is available free of charge on the ACS Publications website at DOI: 10.1021/acscatal.9b03190.

Experimental details, copies of ${ }^{1} \mathrm{H}$ and ${ }^{13} \mathrm{C}$ NMR spectra, computational methods (PDF)

$\mathrm{X}$-ray crystallographic data (CIF)

\section{AUTHOR INFORMATION}

\section{Corresponding Authors}

*Methodology_E-mail: edward.anderson@chem.ox.ac.uk (E. A. Anderson).

*Computation-E-mail: fernanda.duartegonzalez@chem.ox. ac.uk (F. Duarte).

\section{ORCID}

Alistair J. Sterling: 0000-0002-3571-1094

Fernanda Duarte: 0000-0002-6062-8209

Edward A. Anderson: 0000-0002-4149-0494

\section{Author Contributions}

${ }^{\S}$ These authors contributed equally.

\section{Notes}

The authors declare no competing financial interest.

\section{ACKNOWLEDGMENTS}

J.N. thanks the Marie Skłodowska-Curie actions for an Individual Fellowship (GA No 786683). E.A.A. and C.A. thank the EPSRC for support (Nos. EP/M019195/1 and EP/ S013172/1). B.R.S., A.J.S., H.D.P., M.L.J.W., S.J.M. and D.F.J.C. thank the EPSRC Centre for Doctoral Training in Synthesis for Biology and Medicine for studentships (EP/ L015838/1), generously supported by AstraZeneca, Diamond Light Source, Defence Science and Technology Laboratory, Evotec, GlaxoSmithKline, Janssen, Novartis, Pfizer, Syngenta, Takeda, UCB and Vertex. A.J.S. thanks the Oxford-Radcliffe Scholarship for a studentship. A.J.S. and F.D. thank the EPSRC Tier-2 National HPC Facility Service (http://www.cirrus.ac. uk), and the EPSRC Centre for Doctoral Training for Theory and Modelling in Chemical Sciences (No. EP/L015722/1) for providing access to the Dirac Cluster at Oxford. We thank Dr. James R. Donald and the EPSRC Dial-a-Molecule Grand Challenge Network for the gift of photocatalysts for optimization studies (No. EP/P007589/1).

\section{REFERENCES}

(1) (a) Stepan, A. F.; Subramanyam, C.; Efremov, I. V.; Dutra, J. K.; O'Sullivan, T. J.; DiRico, K. J.; McDonald, W. S.; Won, A.; Dorff, P. H.; Nolan, C. E.; Becker, S. L.; Pustilnik, L. R.; Riddell, D. R.; Kauffman, G. W.; Kormos, B. L.; Zhang, L.; Lu, Y.; Capetta, S. H.; Green, M. E.; Karki, K.; Sibley, E.; Atchison, K. P.; Hallgren, A. J.; Oborski, C. E.; Robshaw, A. E.; Sneed, B.; O’Donnell, C. J. Application of the bicyclo[1.1.1]pentane motif as a nonclassical phenyl ring bioisostere in the design of a potent and orally active $\gamma$ secretase inhibitor. J. Med. Chem. 2012, 55, 3414-3424. (b) Measom, N. D.; Down, K. D.; Hirst, D. J.; Jamieson, C.; Manas, E. S.; Patel, V. K.; Somers, D. O. Investigation of a bicyclo[1.1.1]pentane as a phenyl replacement within an LpPLA2 inhibitor. ACS Med. Chem. Lett. 2017, 8, 43-48. (c) Auberson, Y. P.; Brocklehurst, C.; Furegati, M.; Fessard, T. C.; Koch, G.; Decker, A.; La Vecchia, L.; Briard, E. Improving nonspecific binding and solubility: Bicycloalkyl groups and cubanes as para-phenyl bioisosteres. ChemMedChem 2017, 12, 590-598. (d) Goh, Y. L.; Cui, Y. T.; Pendharkar, V.; Adsool, V. A. Toward resolving the resveratrol conundrum: synthesis and in vivo pharmacokinetic evaluation of $\mathrm{BCP}-$ resveratrol. ACS Med. Chem. Lett. 2017, 8, 516-520.

(2) Westphal, M. V.; Wolfstädter, B. T.; Plancher, J.-M.; Gatfield, J.; Carreira, E. M. Evaluation of tert-butyl isosteres: Case studies of physicochemical and pharmacokinetic properties, efficacies, and activities. ChemMedChem 2015, 10, 461-469.

(3) Makarov, I. S.; Brocklehurst, C. E.; Karaghiosoff, K.; Koch, G.; Knochel, P. Synthesis of bicyclo[1.1.1]pentane bioisosteres of internal alkynes and para-disubstituted benzenes from [1.1.1]propellane. Angew. Chem., Int. Ed. 2017, 56, 12774-12777.

(4) (a) Meanwell, N. A. Improving drug design: An update on recent applications of efficiency metrics, strategies for replacing problematic elements, and compounds in nontraditional drug space. Chem. Res. Toxicol. 2016, 29, 564-616. For a review, see: (b) Mykhailiuk, P. K. Saturated Bioisosteres of Benzene: Where to go Next? Org. Biomol. Chem. 2019, 17, 2839-2849. (c) Locke, G. M.; Bernhard, S. S. R.; Senge, M. O. Nonconjugated Hydrocarbons as Rigid-Linear Motifs: 
Isosteres for Material Sciences and Bioorganic and Medicinal Chemistry. Chem. - Eur. J. 2019, 25, 4590-4647.

(5) (a) Gianatassio, R.; Lopchuk, J. M.; Wang, J.; Pan, C.-M.; Malins, L. R.; Prieto, L.; Brandt, T. A.; Collins, M. R.; Gallego, G. M.; Sach, N. W.; Spangler, J. E.; Zhu, H.; Zhu, J.; Baran, P. S. Strainrelease amination. Science 2016, 351, 241-246. (b) Kanazawa, J.; Maeda, K.; Uchiyama, M. Radical multicomponent carboamination of [1.1.1]propellane. J. Am. Chem. Soc. 2017, 139, 17791-17794. (c) Bär, R. M.; Kirschner, S.; Nieger, M.; Bräse, S. Alkyl and Aryl Thiol Addition to [1.1.1]Propellane: Scope and Limitations of a Fast Conjugation Reaction. Chem. - Eur. J. 2018, 24, 1373-1382. (d) Kanazawa, J.; Uchiyama, M. Recent advances in the synthetic chemistry of bicyclo[1.1.1]pentane. Synlett 2019, 30, 1-11. (e) Dilmaç, A. M.; Spuling, E.; de Meijere, A.; Bräse, S. Propellanes-From a chemical curiosity to "explosive" materials and natural products. Angew. Chem., Int. Ed. 2017, 56, 5684-5718.

(6) (a) Daniel Rehm, J. D.; Ziemer, B.; Szeimies, G. A facile route to bridgehead disubstituted bicyclo[1.1.1] pentanes involving palladiumcatalyzed cross-coupling reactions. Eur. J. Org. Chem. 1999, 1999, 2079-2085. (b) Trongsiriwat, N.; Pu, Y.; Nieves-Quinones, Y.; Shelp, R. A.; Kozlowski, M. C.; Walsh, P. J. Reactions of 2-Aryl-1,3-Dithianes and [1.1.1] Propellane. Angew. Chem., Int. Ed. 2019, 58, 1341613420. For a recent example of formal anionic addition at room temperature, see: (c) Shelp, R. A.; Walsh, P. J. Synthesis of BCP Benzylamines From 2-Azaallyl Anions and [1.1.1]Propellane. Angew. Chem., Int. Ed. 2018, 57, 15857-15861.

(7) (a) Kaszynski, P.; McMurdie, N. D.; Michl, J. Synthesis of doubly bridgehead substituted bicyclo[1.1.1]pentanes. Radical transformations of bridgehead halides and carboxylic acids. J. Org. Chem. 1991, 56, 307-316. (b) Kaszynski, P.; Friedli, A. C.; Michl, J. Toward a molecular-size tinkertoy construction set. Preparation of terminally functionalized [n]staffanes from [1.1.1]propellane. J. Am. Chem. Soc. 1992, 114, 601-620. (c) Messner, M.; Kozhushkov, S. I.; de Meijere, A. Nickel- and Palladium-Catalyzed Cross-Coupling Reactions at the Bridgehead of Bicyclo[1.1.1]pentane Derivatives - A Convenient Access to Liquid Crystalline Compounds Containing Bicyclo[1.1.1]pentane Moieties. Eur. J. Org. Chem. 2000, 2000, 1137-1155.

(8) Caputo, D. F. J.; Arroniz, C.; Dürr, A. B.; Mousseau, J. J.; Stepan, A. F.; Mansfield, S. J.; Anderson, E. A. Synthesis and applications of highly functionalized 1-halo-3-substituted bicyclo[1.1.1]pentanes. Chem. Sci. 2018, 9, 5295-5300.

(9) (a) Staveness, D.; Bosque, I.; Stephenson, C. R. J. Free radical chemistry enabled by visible light-induced electron transfer. Acc. Chem. Res. 2016, 49, 2295-2306. (b) Prier, C. K.; Rankic, D. A.; MacMillan, D. W. C. Visible light photoredox catalysis with transition metal complexes: Applications in organic synthesis. Chem. Rev. 2013, 113, 5322-5363. (c) Ravelli, D.; Protti, S.; Fagnoni, M. Carboncarbon bond forming reactions via photogenerated intermediates. Chem. Rev. 2016, 116, 9850-9913. (d) Marzo, L.; Pagire, S. K.; Reiser, O.; König, B. Visible-Light Photocatalysis: Does It Make a Difference in Organic Synthesis? Angew. Chem., Int. Ed. 2018, 57, 10034-10072. (e) Stephenson, C. R. J.; Yoon, T. P.; MacMillan, D. W. C. Visible Light Photocatalysis in Organic Chemistry; Wiley-VCH, 2018.

(10) (a) Barton, D. H. R.; Csiba, M. A.; Jaszberenyi, J. C. $\mathrm{Ru}(\mathrm{bpy})_{3}{ }^{2+}$-mediated addition of Se-phenyl p-tolueneselenosulfonate to electron rich olefins. Tetrahedron Lett. 1994, 35, 2869-2872. (b) Nguyen, J. D.; Tucker, J. W.; Konieczynska, M. D.; Stephenson, C. R. J. Intermolecular atom transfer radical addition to olefins mediated by oxidative quenching of photoredox catalysts. J. Am. Chem. Soc. 2011, 133, 4160-4163. (c) Wallentin, C.-J.; Nguyen, J. D.; Finkbeiner, P.; Stephenson, C. R. J. Visible light-mediated atom transfer radical addition via oxidative and reductive quenching of photocatalysts. J. Am. Chem. Soc. 2012, 134, 8875-8884. (d) Arceo, E.; Montroni, E.; Melchiorre, P. Photo-organocatalysis of atomtransfer radical additions to alkenes. Angew. Chem., Int. Ed. 2014, 53, 12064-12068. (e) Knorn, M.; Rawner, T.; Czerwieniec, R.; Reiser, O. [Copper(phenanthroline)(bisisonitrile)] complexes for the visiblelight-mediated atom transfer radical addition and allylation reactions.
ACS Catal. 2015, 5, 5186-5193. (f) Wang, L.; Lear, J. M.; Rafferty, S. M.; Fosu, S. C.; Nagib, D. A. Ketyl radical reactivity via atom transfer catalysis. Science 2018, 362, 225. (g) Courant, T.; Masson, G. Recent progress in visible-light photoredox-catalyzed intermolecular 1,2difunctionalization of double bonds via an ATRA-type mechanism. J. Org. Chem. 2016, 81, 6945-6952. (h) Seath, C. P.; Vogt, D. B.; Xu, Z.; Boyington, A. J.; Jui, N. T. Radical Hydroarylation of Functionalized Olefins and Mechanistic Investigation of Photocatalytic Pyridyl Radical Reactions. J. Am. Chem. Soc. 2018, 140, 15525-15534.

(11) (a) Subsequent to the deposition of this work on a preprint server, an elegant photoredox Giese reaction with bicyclo[1.1.0] butanes was reported. See: Guillaume, E.; Egor, C.; Lydia, R.; Ponnadurai, R.; Jean-Christophe, C. Photochemical Strain-Release Driven Cyclobutylation of C(sp3)-Centered Radicals. ChemRxiv 2019, Preprint 8323406.v1. For a visible light promoted radical addition to bicyclo[1.1.0] butanes that proceeds in the absence of a photoredox catalyst, see: (b) Silvi, M.; Aggarwal, V. K. Radical Addition to Strained $\sigma$-Bonds Enables the Stereocontrolled Synthesis of Cyclobutyl Boronic Esters. J. Am. Chem. Soc. 2019, 141, 95119515.

(12) See the Supporting Information for details.

(13) Shen, Y.; Cornella, J.; Juliá-Hernández, F.; Martin, R. Visiblelight-promoted atom transfer radical cyclization of unactivated alkyl iodides. ACS Catal. 2017, 7, 409-412.

(14) Moderate thermal decomposition of TCP is observed over the course of the reaction; as such, the organohalide was used as the limiting reagent.

(15) Resubmission of the BCP iodide product 3 to the reaction conditions did not lead to staffane formation, suggesting the product is unreactive toward further photoredox-catalyzed ATRA chemistry under these conditions. Staffane formation of $<5 \%$ was observed for all examples.

(16) (a) Kim, H.; Lee, C. Visible-Light-Induced Photocatalytic Reductive Transformations of Organohalides. Angew. Chem., Int. Ed. 2012, 51, 12303-12306. (b) Nguyen, J. D.; D’Amato, E. M.; Narayanam, J. M. R.; Stephenson, C. R. J. Engaging unactivated alkyl, alkenyl and aryl iodides in visible-light-mediated free radical reactions. Nat. Chem. 2012, 4, 854-859. (c) Tucker, J. W.; Nguyen, J. D.; Narayanam, J. M. R.; Krabbe, S. W.; Stephenson, C. R. J. Tin-free radical cyclization reactions initiated by visible light photoredox catalysis. Chem. Commun. 2010, 46, 4985-4987.

(17) (a) Gu, X.; Lu, P.; Fan, W.; Li, P.; Yao, Y. Visible light photoredox atom transfer Ueno-Stork reaction. Org. Biomol. Chem. 2013, 11, 7088-7091. (b) Weng, W.-Z.; Liang, H.; Liu, R.-Z.; Ji, Y.X.; Zhang, B. Visible-Light-Promoted Manganese-Catalyzed Atom Transfer Radical Cyclization of Unactivated Alkyl Iodides. Org. Lett. 2019, 21, 5586-5590.

(18) For distinct two component ATRC processes in which the cyclization takes place in the second reaction component, see: (a) Yoshioka, E.; Kohtani, S.; Tanaka, E.; Hata, Y.; Miyabe, H. Carbon radical addition-cyclization reaction induced by rutheniumphotocatalyst under visible light irradiation. Tetrahedron 2015, 71, 773-781. (b) Ueda, M.; Miyabe, H.; Nishimura, A.; Miyata, O.; Takemoto, Y.; Naito, T. Indium-Mediated Tandem Radical Addition-Cyclization-Trap Reactions in Aqueous Media. Org. Lett. 2003, 5, 3835-3838.

(19) Beckwith, A. L. J. Regio-selectivity and stereo-selectivity in radical reactions. Tetrahedron 1981, 37, 3073-3100.

(20) Low-temperature single-crystal X-ray diffraction data for $\mathbf{7 6}$ and 86 were collected with a (Rigaku) Oxford Diffraction SuperNova A diffractometer at $150 \mathrm{~K}$. All data were reduced using CrysAlisPro, solved using SuperFlip [ Palatinus, L.; Chapuis, G. J. Appl. Crystallogr. 2007, 40, 786-790 ] and the structures were refined using CRYSTALS . Betteridge, P. W.; Carruthers, J. R.; Cooper, R. I.; Prout, K.; Watkin, D. J. J. Appl. Crystallogr. 2003, 36, 1487. Cooper, R. I.; Thompson, A. L.; Watkin, D. J. J. Appl. Crystallogr. 2010, 43, 1100-1107. The Flack $(x)$ parameter [ Flack, H. D. Acta Crystallogr., Sect. A: Found. Crystallogr. 1983, 39, 876-881. Flack, H. D.; 
Bernardinelli, G. J. Appl. Crystallogr. 2000, 33, 1143-1148 ] was refined in all cases; see the CIF file in the Supporting Information for further details. (CCDC 1905036-1905037 contains the supplementary crystallographic data for this paper) .

(21) Hazra, A.; Lee, M. T.; Chiu, J. F.; Lalic, G. Photoinduced copper-catalyzed coupling of terminal alkynes and alkyl iodides. Angew. Chem., Int. Ed. 2018, 57, 5492-5496.

(22) Flamigni, L.; Barbieri, A.; Sabatini, C.; Ventura, B.; Barigelletti, F. In Photochemistry and Photophysics of Coordination Compounds II; Balzani, V., Campagna, S., Eds.; Springer: Berlin, Heidelberg, Germany, 2007; pp 143-203.

(23) For previous computational work on [1.1.1]propellane ring opening, see refs $5 b, 6 b$, and 8 .

(24) (a) Peterson, K. A. Systematically convergent basis sets with relativistic pseudopotentials. I. Correlation consistent basis sets for the post-d group 13-15 elements. J. Chem. Phys. 2003, 119, 1109911112. (b) Weigend, F.; Ahlrichs, R. Balanced basis sets of split valence, triple zeta valence and quadruple zeta valence quality for $\mathrm{H}$ to $\mathrm{Rn}$ : Design and assessment of accuracy. Phys. Chem. Chem. Phys. 2005, 7, 3297-3305. (c) Grimme, S. Semiempirical hybrid density functional with perturbative second-order correlation. J. Chem. Phys. 2006, 124, 034108. (d) Marenich, A. V.; Cramer, C. J.; Truhlar, D. G. Universal Solvation Model Based on Solute Electron Density and on a Continuum Model of the Solvent Defined by the Bulk Dielectric Constant and Atomic Surface Tensions. J. Phys. Chem. B 2009, 113, 6378-6396. (e) Isegawa, M.; Neese, F.; Pantazis, D. A. Ionization Energies and Aqueous Redox Potentials of Organic Molecules: Comparison of DFT, Correlated ab Initio Theory and Pair Natural Orbital Approaches. J. Chem. Theory Comput. 2016, 12, 2272-2284. (f) Neese, F. Software update: the ORCA program system, version 4.0. Wiley Interdisciplinary Reviews: Computational Molecular Science 2018, 8, e1327. 